\title{
Antipyrene preparation based on phosphoric acid with carbamide
}

\author{
Olimova Mohinur Karimjon qizi ${ }^{1}$ \\ ${ }^{1}$ Assistant of Kokand branch of Tashkent state technical University named after Islam Karimov \\ Email: olimova_m@umail.uz
}

\begin{abstract}
In this work, we have carried out research on the synthesis of nitrogen and phosphorus-containing fire retardants. Epichlorohydrin, urea, melamine, ammonium dihydrogen phosphate, orthophosphoric acid, morpholine were selected as objects of research.
\end{abstract}

Keywords: phosphoric, nitrogen, retardant, antipyrene, polymer, flame, polycondensation of orthophosphoric.

\section{INTRODUCTION}

The use of flame retardants changes the behavior of flammable materials in a fire, reducing or suppressing their flammability. Flame retardants can be added both during and after the production of flammable materials, or in some cases used as a reagent for the production of a chemically modified polymer. Most organic substances, both synthetic and natural, are inherently flammable. Flame retardants can alter the reaction of a substance to combustion, imparting a flame retardant property to the substance, which leads to a slower combustion rate when ignited. Fire retardants provide invaluable time to rescue people from buildings engulfed in flames.

There are several types of flame retardants, however, phosphorus-based flame retardants are considered superior. Because the combustion of phosphorus-containing flame retardants does not form carcinogenic substances such as dioxins or furans. In connection with the recent increased interest in the problems of environmental pollution and harm to human health, halogen-based flame retardants are constantly being replaced by more environmentally friendly phosphorus- and nitrogen-containing flame retardants.

The influence of various technological parameters on the process of polycondensation of orthophosphoric acid and carbamide has been studied. The interaction of urea with phosphoric acid occurs in the liquid phase with vigorous stirring and heating of the reaction mass:

$$
\mathrm{NH}_{2} \mathrm{CONH}_{2}+(\mathrm{HO})_{3} \mathrm{PO} \longrightarrow \mathrm{NH}_{2} \mathrm{C}(\mathrm{O}) \mathrm{NH} \cdot \mathrm{P}(\mathrm{O}) \cdot(\mathrm{OH})_{2}+\mathrm{H}_{2} \mathrm{O}
$$

By carrying out a number of laboratory experiments, the optimal dilution ratio was selected. It was found that at atmospheric pressure and $90^{\circ} \mathrm{C}$ and a molar ratio of carbamide: orthophosphoric acid: water 2.3: $1: 5$, it is possible to obtain a homogeneous reaction mass.

The study of the reaction kinetics shows that the reaction is characterized by a low rate. In this regard, we have carried out research to accelerate the polycondensation reaction. The rate of reaction of urea with phosphoric acid was determined from the time it took to reach the $\mathrm{pH}$ of the reaction medium equal to 4 . At this value of the acidity of the medium, approximately $50 \%$ of the conversion of the starting reagents is achieved; therefore, this parameter is chosen for the convenience of measurements. It was found that the intensity of stirring does not affect the reaction rate; the reaction is not complicated by diffusion inhibition and proceeds in the kinetic region. As the temperature rises from 70 to $90^{\circ} \mathrm{C}$, the reaction rate increases (figure). An increase in the concentration of urea increases the rate of polycondensation. However, an excess of urea creates conditions for its precipitation at low temperatures.

Also, we obtained an oligomeric fire retardant by condensation of carbamide with orthophosphoric acid in the melt at a temperature of $130-135{ }^{\circ} \mathrm{C}$. The synthesis of the oligomer in the melt excludes the hydrolysis of the starting carbamide. The molar ratio of carbamide and phosphoric acid during the synthesis is (1.5-2.5): 1, which corresponds to the atomic ratio N / P from 3 to 5 and the yield is $95-98 \%$. The resulting fire retardants dissolve in water and some organic solvents. 


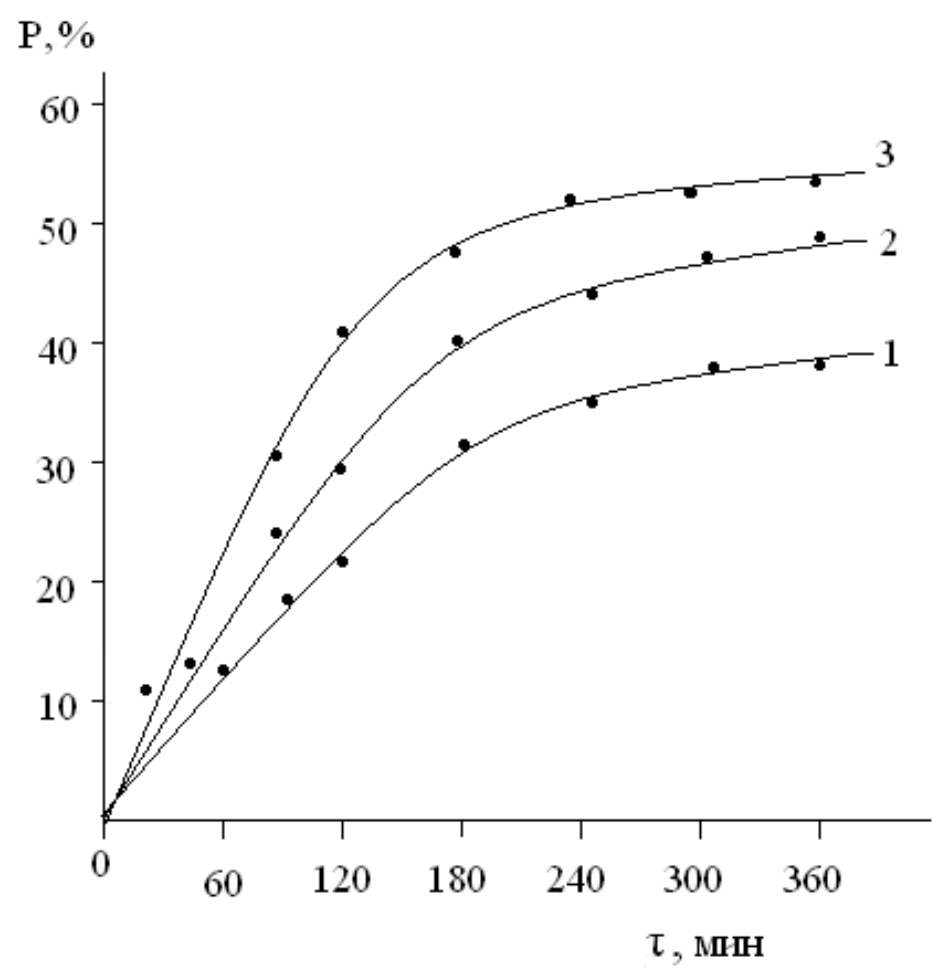

Figure 1. Kinetics of polycondensation of phosphoric acid with carbamide at temperatures, ${ }^{\circ} \mathrm{C}: 1-70,2-80$, $3-90$.

The structure of oligomers obtained by combined polycondensation of carbamide and orthophosphoric acid was studied by the methods of elemental analysis and IR spectroscopy. The influence of synthesis conditions on the value of intrinsic viscosity was studied by the method of viscometry.

The reaction of interaction of carbamide with ammonium dihydrogen phosphate in the melt has been studied. It has been experimentally established that a by-product of this reaction is ammonium hydroxide $\mathrm{NH}_{4} \mathrm{OH}$, when heated, ammonia is formed. To interact with ammonium hydroxide, orthophosphoric acid was introduced into the reaction zone. As a result of the reaction, ammonium dihydrogen phosphate is formed, which is involved in the synthesis of a fire retardant. The general scheme for the synthesis of a fire retardant based on carbamide with ammonium dihydrogen phosphate can be represented by the following scheme:

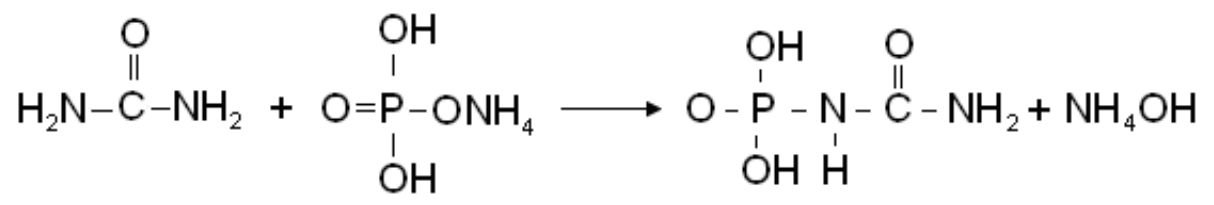<smiles>N[NH2+]NC(=O)NP(O)(O)(O)O</smiles>

Thus, the binding of the released $\mathrm{NH}_{4}+$ ion with phosphoric acid ensures its use as a reagent for endogenous feeding of the synthesis components with an additional amount of ammonium phosphate and a more complete course of the overall condensation reaction.

Next, we synthesized oligomeric fire retardants by polymerizing epichlorohydrin with a phosphoruscontaining compound. Ammonium dihydrogen phosphate was used as a phosphorus-containing compound.

The epichlorohydrin molecule contains two active groups - an epoxy and a $\mathrm{C}-\mathrm{Cl}$ bond. The epoxy cycle is an almost regular triangle with significantly deformed bond angles. Therefore, only partial overlapping of atomic orbitals occurs and the bond energy decreases: 

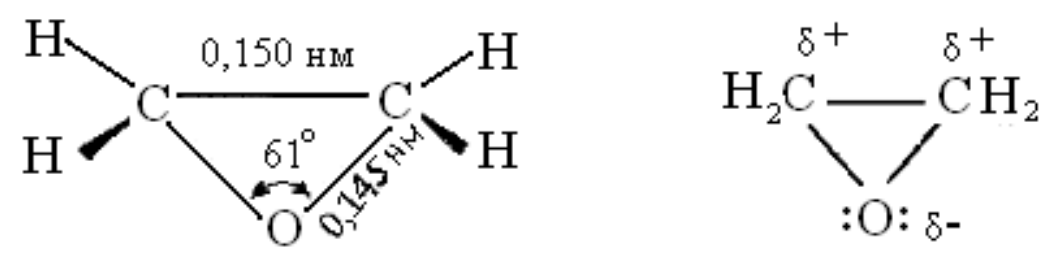

The polymerization process was carried out by stirring at temperatures of $20-40^{\circ} \mathrm{C}$. The structural formula of the synthesized compound based on epichlorohydrin with ammonium dihydrogen phosphate can be represented as follows:

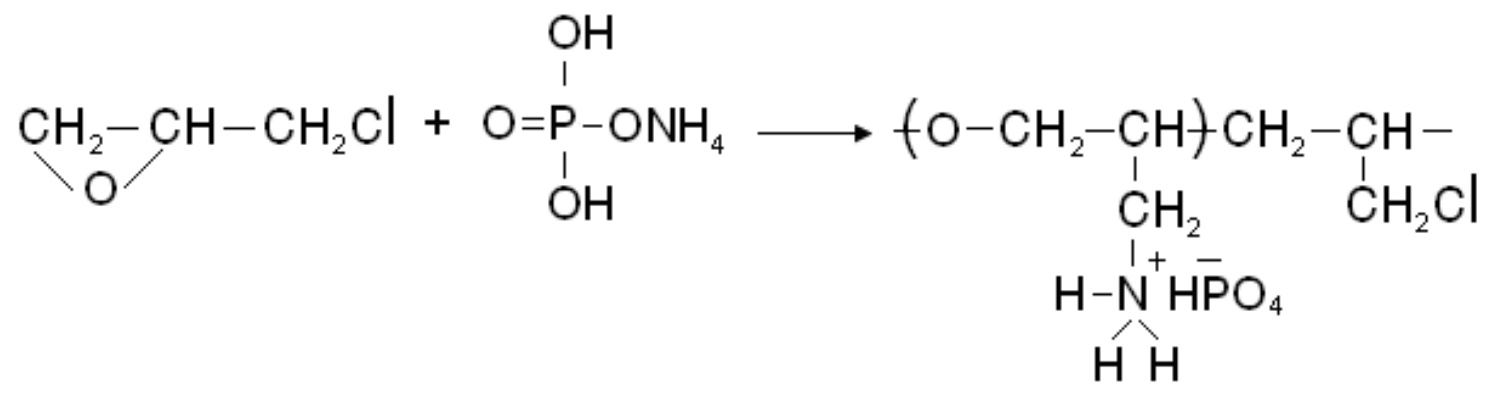

The influence of various technological factors on the polymerization process was studied: the ratio of the initial reagents, the nature of the solvent, and temperature.

Study of the influence of the ratio of the initial reagents on the yield of the oligomeric product shows that with an increase in the ratio of ammonium dihydrogen phosphate.

In order to study the fire-retardant properties of synthesized products on cotton fabrics, we impregnated fabrics with an aqueous composition containing $25-30 \%$ of a fire retardant based on carbamide with orthophosphoric acid, followed by pressing (25-30\%). Then it was dried at $50-60{ }^{\circ} \mathrm{C}$ and heat treated at $140-150{ }^{\circ} \mathrm{C}$ for 5 minutes. It was found that the use of the specified fire retardant increases the effect of non-combustibility of the fabric.

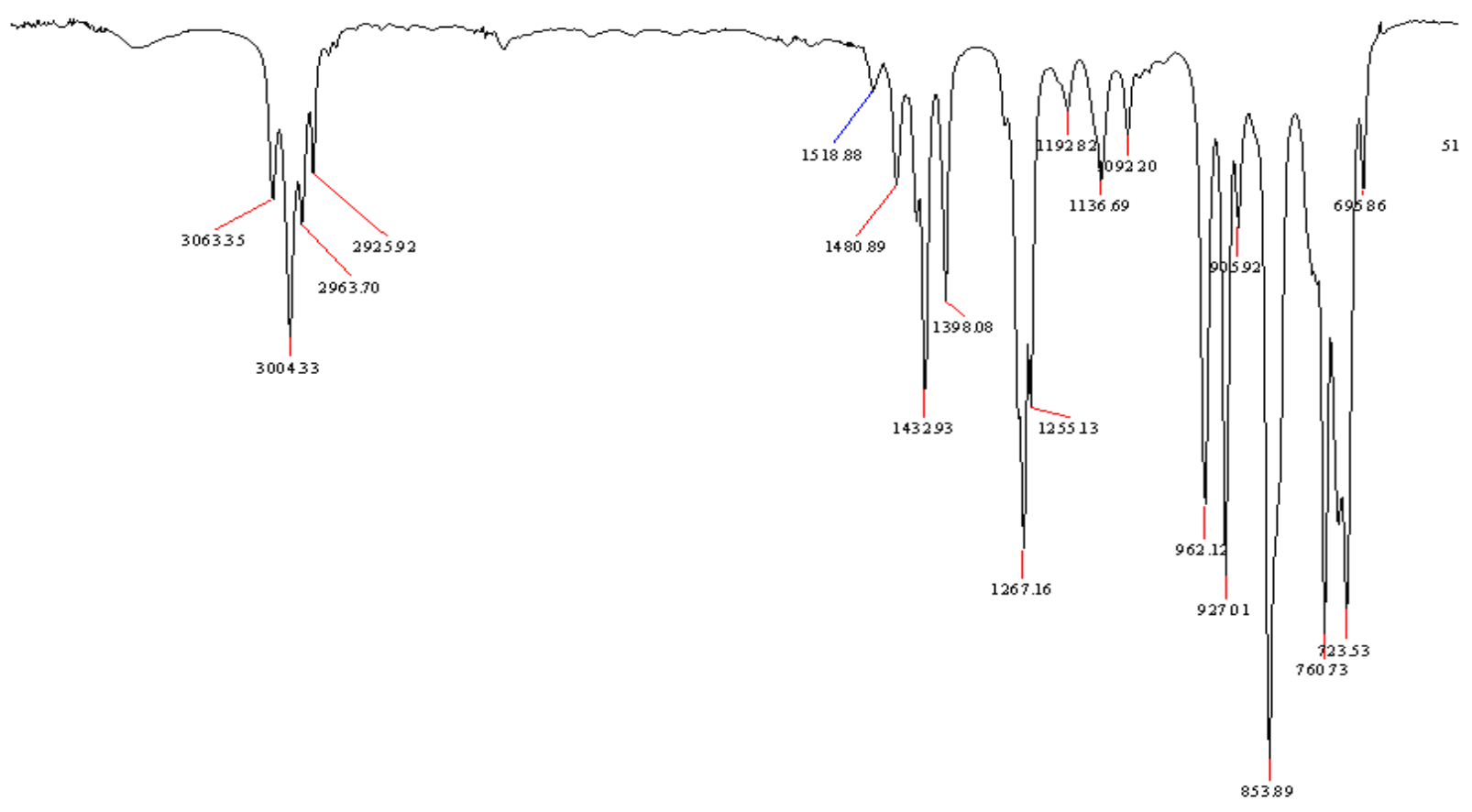

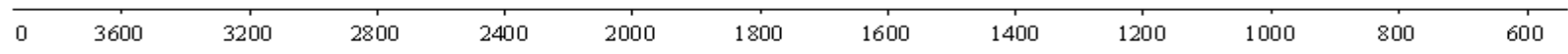




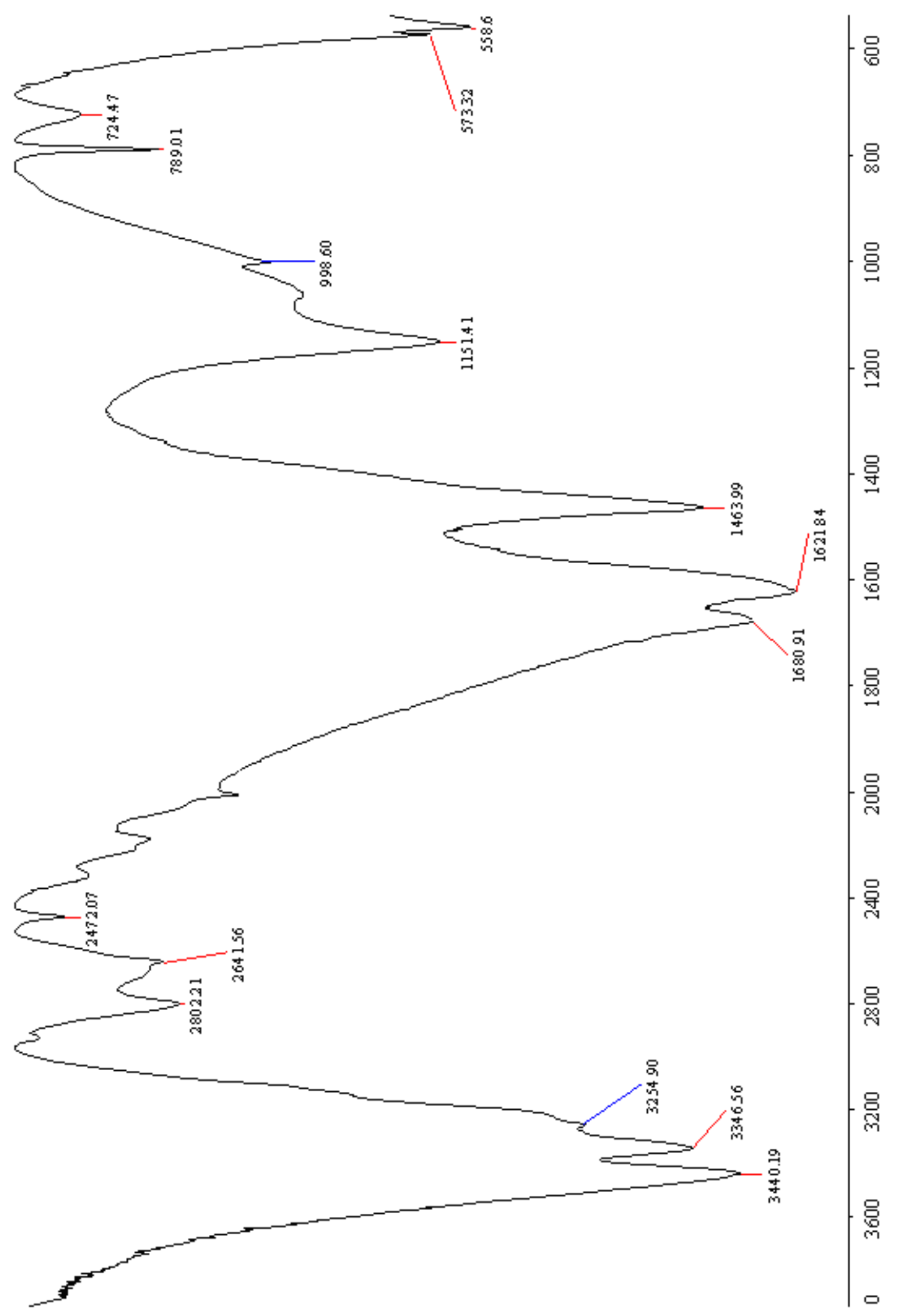




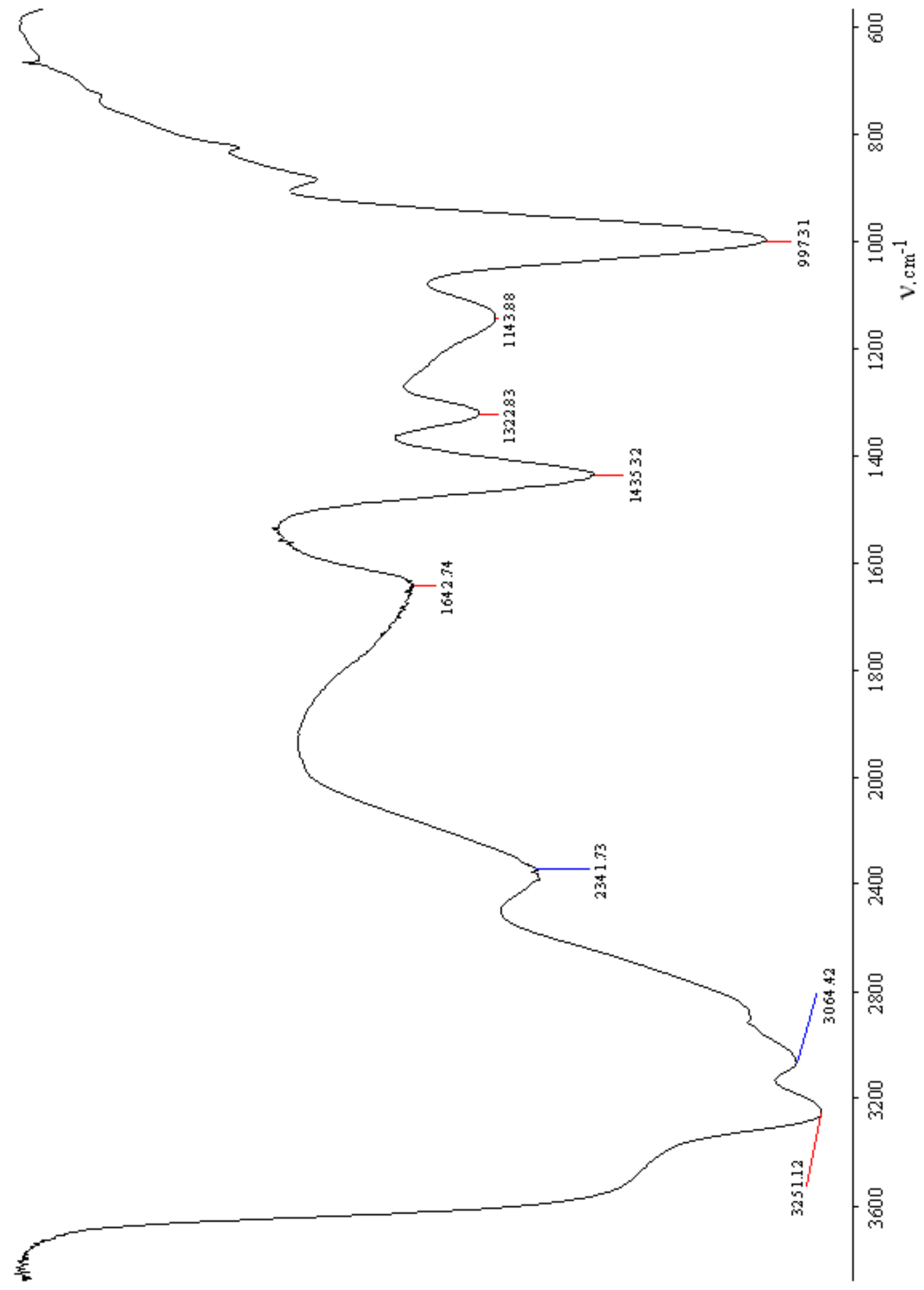




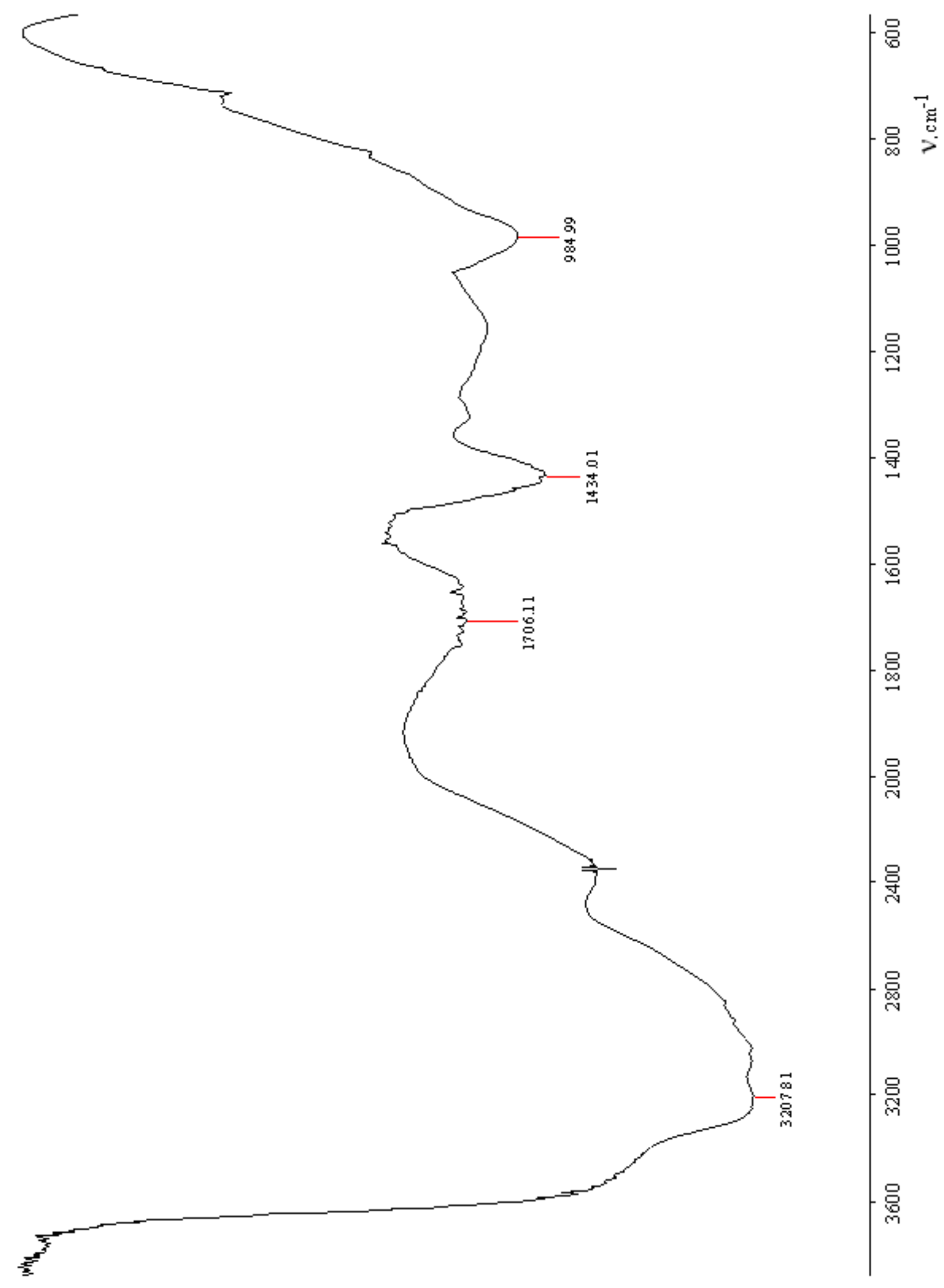




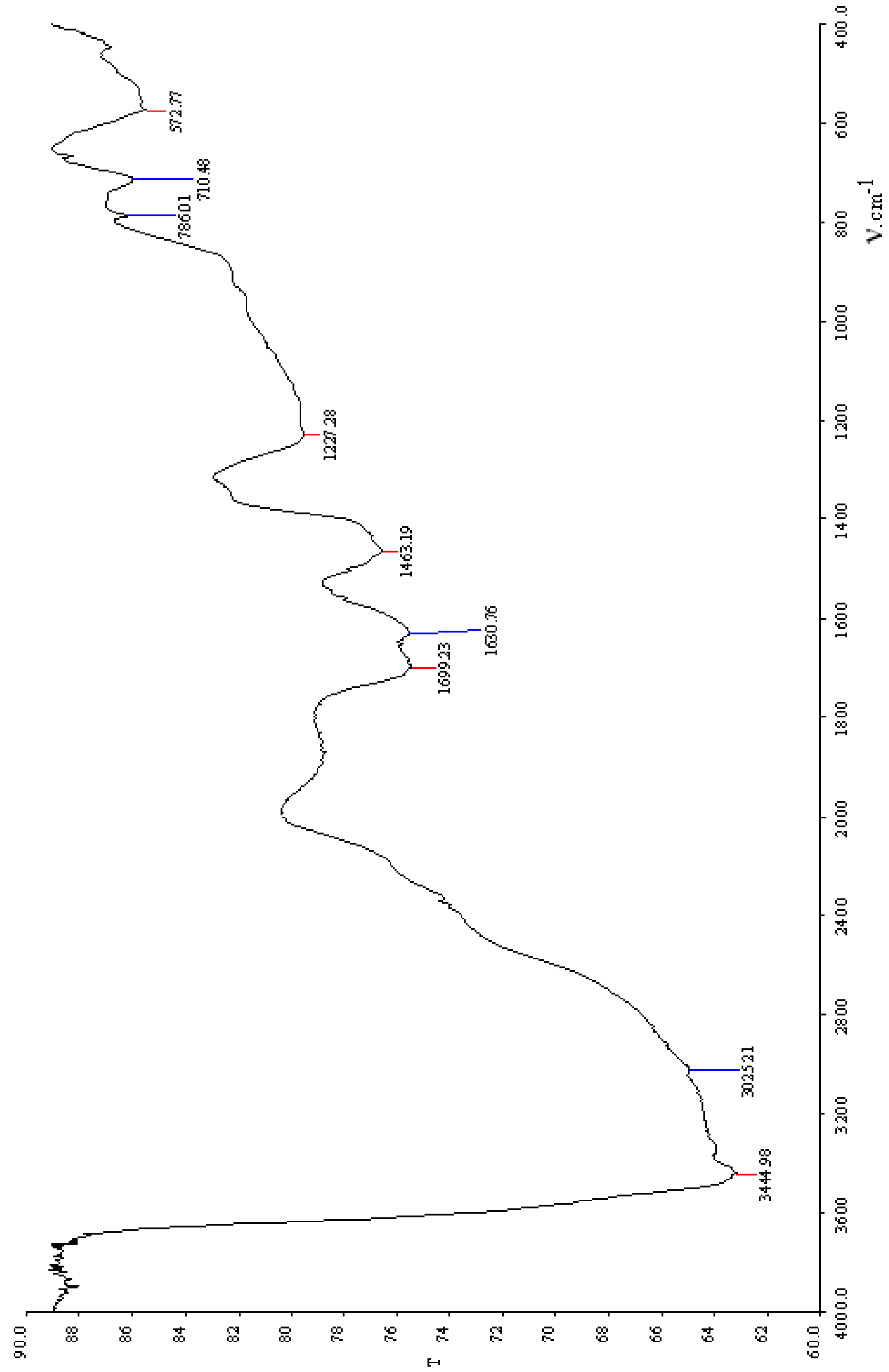




\section{REFERENCES}

* Plastics Flammability Handbook. Principles, Regulations, Testing, and Approval. - 3rd ed. / Ed. by Jurgend Troitzsch. - Munich: Carl Hanser Verlag, 2004. - 718 p.

* Fire retardancy of polymeric materials/ Ed. By A.F. Grand, C.A. Wilkie. - New York: Narsel Dekker, Inc., 2000. -302 p.

* Sanghyun Hong, Jaeho Yang, Sunghee Ahn, Yongik Mun, Gyucheol Lee. Flame retardant performance of various UL94 classified materials exposed to external ignition sources // Fire and Materials, 2004. - Vol. 28, Iss. 1, P. 25. - 3123. 24. Novel phosphorus\&modified polysulfone as a combined flame retardant and toughness modifier for epoxy resins / R.M. Perez, J.K.W. Sandler, V. Altstdt, et al. // Polymer, 2007. - Vol. 48. - Iss. 3. - P. 778-790.

* Flame retardant synergism of rubber and $\mathrm{Mg}(\mathrm{OH})_{2}$ in EVA composites / Gui H., Zhang X., Dong W. et al. // Polymer, 2007. - Vo. 48. - Iss. 9. - P. 2537-2541.

* Li G., Liang G., He T., Yang Q., Song X. Effects of EG and MoSi 2 on thermal degradation of intumescent coating // Polymer Degradation and Stability, 2007. - Vol. 92. - Iss. 4. - P/ 569-579.

* Study on preparation and fire\&retardant mechanism analysis of intumescent flame-retardant coatings / Gu J., Zhang G., Dong S., et al. // Surface and Coatings Technology2007. - Vol. 201. - Iss. 18. - P. 7835-7841.

* Thermal stability and flame retardancy of LDPE/EVA blends filled with synthetic hydromagnesite/aluminium hydroxide/montmorillonite and magnesium hydroxide/aluminium hydroxide/montmorillonite mixtures. Haurie L., Fernandez A.I., Velasco J.I., et al. // Polymer Degradation and Stability, 2007. - Vol. 92. - Iss. 6. - P. 1082-1087.

\section{Appendix}

1) Ик-спектры антипирена на основе мочевины с ортофосфорной кислоты, синтезированные в массе IC - spectra of a fire retardant based on urea with orthophosphoric acid synthesized in bulk

2) Ик -спектры антипирена на основе мочевины с ортофосфорной кислоты, синтезированные в среде воды - IC - spectra of a fire retardant based on urea with orthophosphoric acid, synthesized in water

3) Ик - спектры антипирена на основе мочевины и ортофосфорной кислоты, синтезированные в среде воды - IC - spectra of a fire retardant based on urea and orthophosphoric acid, synthesized in water

4) Ик - спектры мочевины - IC - urea spectra

5) Ик - спектры эпихлоргидрина - IC- epichlorohydrin spectra 